\title{
Halkla İlişkilerin Gazetelerde Sunumuna Yönelik Bir Analiz
}

\author{
Özgür Kılınç (Dr. Öğr. Üyesi) \\ İnönü Üniversitesi İletişim Fakültesi \\ ozgur.kilinc@inonu.edu.tr \\ ORCID: 0000-0002-8697-162X
}

Başvuru Tarihi: 05.11.2019

Yayına Kabul Tarihi: 12.12.2019

Yayınlanma Tarihi: 24.01.2020

DOI: http://10.17680/erciyesiletisim.643134

\section{Öz}

Medya çeşitli konuları ve terimleri okuyucuya / izleyiciye / dinleyiciye aktarırken konuların ve kavramların bazı boyutlarını daha fazla vurgular iken; bazı boyutlarını ise daha geri planda bırakmaktadır. Yönetimsel bir fonksiyon olarak halkla ilişkiler medyada çeşitli içerikler ile yer almaktadır. Filmler, gazete haberleri halkla ilişkiler teriminin nasıl sunulduğunu incelemeyi mümkün kılan içerikleridir. Dolayısıyla halkla ilişkiler de medyada sunulan içeriklere konu olmaktadır. Bu kapsamda çalışmanın amacı halkla ilişkiler teriminin medyada sunulma biçimini incelemektir. Belirlenen zaman aralığında dört gazetede halkla ilişkiler terimini içeren 73 haber içerik analizi tekniği ile analiz edilmiștir. Araştırma sonuçları halkla ilişkiler teriminin köșe yazısı ve röportaja kıyasla daha çok haber içeriklerinde öne çıktığını, terimin kar amacı taşımayan kurumlar bağlamında kullanımının daha fazla olduğunu ortaya koymuştur. Amaç kapsamında halkla ilişkilerin bilgilendirme amacının en fazla belirgin olan amaç kategorisi olduğu saptanmıştır. Haber içeriklerinin çoğunda halkla ilişkiler terimi nötr bir şekilde sunulmuştur.

Anahtar Kelimeler: Halkla İlişkiler, Medyada Halkla İlişsiler, Halkla İlişkilerin Sunumu. 


\title{
An Analysis of Presentation of Public Relations in Newspapers
}

\author{
Özgür Kılınç (Asst. Prof. Dr.) \\ İnönü University Faculty of Communication \\ ozgur.kilinc@inonu.edu.tr \\ ORCID: 0000-0002-8697-162X
}

Date Received: 05.11.2019

Date Accepted: 12.12.2019

Date Published: 24.01.2020

DOI: http://10.17680/erciyesiletisim.643134

\begin{abstract}
Ahstractia emphasizes some aspects of the subjects and concepts more while transferring various topics and terms to the audience while leaving some aspects of them more behind. As a managerial function, public relations takes place in the media with various content. Films, newspaper news are the content that make it possible to examine how the term public relations is presented. Thus, public relations is also the subject of content presented in the media. In this context, the objective of the study is to examine how the term public relations is presented in the media. In the determined time period, 73 news stories, which include the term public relations, in four newspapers were analysed by content analysis technique. The results of the research revealed that the term public relations was more prominent in the news content than the column articles and interview, and the term was more used in the context of non-profit organizations. Within the scope of the purpose, it was determined that the purpose of public information was the most prominent category. In most of the news content, the term public relations is presented in a neutral form.
\end{abstract}

Keywords: Public Relations, Public Relations in Media, Presentation of Public Relations. 


\section{Giriş}

Halkla ilişkiler, iletişim ve ilişki inşasına yönelik bir yönetim fonksiyondur. İlgili kamular ile ilişki kurmada halkla ilişkilerin tarihsel seyrinin ikna, iletişim ve ilișki üzerine yapılandırıldığı söylenebilir. Öte yandan bu iletişimsel pratik temel olarak bir yönetim fonksiyonu olarak tanımlansa da halkla ilişsilerin medyada yer alma biçiminin başka bir deyişle halkla ilișkilerin, halkla ilişkileri genel olarak olumsuz bir söylem üzerinden sunulmaktadır. Alan kendisini ikna, iletişim ve ilişki ya da Hutton'ın (1999, s. 205) deyimiyle "inisiyatif, ilgi ve imaj" kavramları üzerinden tanımlasa da halkla ilișkiler alanının kendini tanımlama biçimi ile alana yönelik algı arasında bir çelişki bulunmaktadır.

Stratejik kamuları, stratejik yönetim süreçlerinin birer parçası olarak saptayarak, yönetim ve söz konusu kamular arasında uzun süreli ve etkili bir ilişki inşa etmek ve sürdürmek için iletişim programları yürüten halkla ilişkilerin (Hon ve Grunig, 1999, s. 9) sürekli bir imaj sorunu olmuştur (Zoch, Supa ve VanTuyll, 2014, s. 723). Thurlow ve Yue (2015, s. 31) İkinci Dünya Savaşı'ndan bu yana, Kanada'da ve ABD'de popüler kültür, ana akım medya, sinema ve kurgusal yazılar aracılığıyla tasarlanan halkla ilişkiler pratiği imajının kesinlikle olumsuz olduğunu ifade etmektedir. Bahsi geçen araştırmacılar 1940’lardan önce ise popüler kültür içindeki halkla ilişkiler tasvirinin oldukça olumlu olduğunu ifade ederek, savaş sonrası dönemde vurgulanan propagandaya artan odaklanma ya da bu yıllardan sonra halkla ilişkiler uygulayıcılarının sayısındaki artış ile mesleğin temsilinde de belirgin bir değișiklik olduğunu dile getirmektedir.

Medya temsilcileri ve gazeteciler sıklıkla belirsiz bir halkla ilişkiler imajına sahiptir. Temsilciler ve gazeteciler halkla ilişsilerin bir bilgi kaynağı olarak vazgeçilmez olduğunu onaylamakta fakat aynı zamanda "PR şakası", "PR oyunu" ve "tipik PR" gibi nitelemeleri sıklıkla kullanmaktadır (Bentele ve Junghänel, 2004, s. 164). Halkla ilişkiler alanının imajı farklı kamular arasında da değişmektedir. Halkla ilişkiler kamu tarafından genel olarak doğrudan hissedilmeyip, imajı daha dolaylı bir şekilde yaymaktadır (Bentele ve Wehmeier, 2003, s. 203). Callison'ın (2001, s. 219) ifade ettiği gibi her ne kadar çoğu halkla ilişkiler uygulayıcısı temsil ettikleri kurumun / kişinin olumlu imajını korumak için çalışsa da meslek, nadiren halkla ilişkilerin imajına yönelik kampanya yapmakta ve sonuç olarak, çeşitli kamular arasında pozitif ilişkilerin yaratılmasına odaklanan bir alanın etkilemeye çalıştığı kamudan önce kendi itibarını korumanın zorluğuyla karşı karşıya kalmaktadır.

Halkla ilişkiler alanının kendini nasıl tanımladığı ile kamunun bu alanı nasıl anladığı arasındaki kopukluk, halkla ilişkilerin medyada nasıl betimlendiği ile açıklanabilir bir nitelik taşımaktadır (Penning, 2008, s. 345). Medyanın etki alanının genişliği ve çeşitli kavramların, içeriklerin medyada çerçevelenip okuyucuya / izleyiciye / dinleyiciye sunulmasının etkileri düşünüldügünde halkla ilişkilerin medya temsili incelemeye değer görünmektedir. Halkla ilişkilerin medyada sunulma biçiminin, terimin ve dolayısıyla uygulamanın nasıl algılandığının daha iyi anlaşılmasını sağlayabileceği (Jo, 2003, s. 398) çıkarımından hareketle çalışmanın amacı halkla ilişkiler kavramının gazetelerdeki sunumunu incelemektir. Söz konusu amaç doğrultusunda belirlenen dört gazetede halkla ilişkiler kavramının yer aldığı 73 haber incelenmiştir. Çalışmada ilk olarak medyada halkla ilişkilerin sunumuna yönelik yapılan önceki çalışmalara değinilmekte, bu başlığı ise yöntem, bulgular ve sonuç başlıkları takip etmektedir.

\section{Medyada Halkla İlişkilerin Sunumu}

Medya, anlamları inşa etmekte, okuyucuları / izleyici / dinleyicileri eğitmekte ve etkilemekte, mesajları ve değerleri iletmektedir (Mac ve Blum, 2013, s. 49). 21. 
yüzyılda, insanlık tarihinde benzeri görülmemiş geniş bir medya ortamının kullanıldığı düşünüldüğünde (Croteau ve Hoynes, 2003, s. 3) ve temsiller, dünyanın ne olduğunu, neden ve nasıl belli şekillerde çalıştığını anlamak için imgeler, açıklamalar ve çerçeveler olduğundan (Hall, 1997) medyada bir kavramın temsilini incelemek önem taşımaktadır. Medyadaki temsil, karakterlerin, fikirlerin, konuların ve olayların okuyucuya / izleyiciye / dinleyiciye sunulma şekliyle ilgilidir (Trbic, 2007, s. 87). Robinson (2009, s. 497) araştırmacıların uzun zamandır medyada kavramların nasıl tasvir edildiği ile ilgilendiklerini ve bunun temel nedeninin de medyanın günlük yaşamdaki yaygınlığından kaynaklandığını dile getirmektedir. Başka bir deyişle kitle iletişim araçları sosyal ilişkileri oluşturmada, sürdürme veya değiştirmede kurumsal ve kültürel bir rol oynamaktadır (King, 2000, s. 232). Söz konusu rol, kitle iletişim araçlarının etki içeriği tartışmalarını da beraberinde getirmektedir. Kitle iletişim araçlarının etki potansiyeli çeşitli iletişimsel içerikler üzerinden somutlaşmaktadır. Filmler, gazete haberleri, diziler, haber bültenleri ve reklamlar bu içeriklerden birkaçıdır.

Popüler kültürün önde gelen bir bileșeni olarak filmler, belirli bir konunun, kurumun veya mesleğin imajını betimleme ve etkileme gücüne sahiptir (Lee, 2004, s. 157). Medya tasvirine yönelik çalışmalar medyanın "toplumun aynası" olması ve "sosyal etki" gibi yaklaşımlar temel alınarak incelenebileceği gibi Bandura'nın "Sosyal Öğrenme Teorisi", Gerbner'in "Ekme Kuramı" ve "Gündem Belirleme Kuramı" gibi kuramlar da temel alınarak incelenebilir (Robinson, 2009). Medya etkilerinin incelenmesi, kitle iletişiminin bireyler, toplum ve kültür üzerinde gözle görülür etkileri olduğu inancına dayanmaktadır (Perse ve Lambe, 2017, s. 22).

Bir iletişimsel pratik olarak halkla ilişkilerin de medya ile olan ilişkisinin öncelikle "medya ilişkileri” olarak adlandırılan ve medya ile yürütülen ilişki şeklinde tanımlanabilecek uygulama alanı ve kavramın medyada yer alması ile somutlaştığı söylenebilir. Medya, halkla ilişkiler alanı için kurumsal faaliyetlerin aktarılabileceği bir araç ve önemli bir paydaş konumundadır.

Öncelikle bilgiyi, imajı ve paydaş ilişkisini yönetmek için çalıșan halkla ilişkiler, büyüklüğü ve etki alanı ile modern medya ortamında önemli bir rol oynamaktadır (Chorazy ve Harrington, 2017, s. 229). Halkla ilişkiler uygulayıcılarının filmlerdeki ve televizyondaki temsillerine yönelik ilgi 1970'lerden bu yana daha yaygın hale gelmiștir (Saltzman, 2011). Halkla ilişkilerin kitle iletişim araçlarında nasıl tasvir edildiğine dair bazı gözlemler karikatürleștirme, çarpıtmalar ve klișeler olduğu sonucuna ulaşmıștır (Hutton ve Mak, 2014, s. 585). Lambert, Strauss ve Tindall'ın (2016, s. 90) vurguladığı gibi son yıllarda halkla ilişkiler temsilcileri profesyonel kimliklerine, sosyal statülerine ve kişisel ilişkilerine yönelik izleyici varsayımlarını şekillendirmektedir.

Miller'e göre (1999, s. 4) halkla ilişkiler araştırmacıları ve uygulayıcıları uzun zamandır insanların, halkla ilişkiler ve uygulayıcıları algılama biçimleriyle ilgili endişelerini dile getirmektedir. Lambert de (2017, s. 751) halkla ilişkiler mesleğine yönelik toplumsal anlayışın sorunlu olduğunu belirtmektedir. Haber medyası, halkla ilişkilerin rolü, amacı ve işlevleri hakkındaki yanlış bilgi kaynaklarından sadece bir tanesi olup eğlence medyası da halkla ilişkiler ile ilgili olumsuz klişelerin çoğunu sürdürmekten sorumludur. Dolayısıyla televizyon programları ve filmler halkla ilişkilerin sunumu konusunda sayısız örnekler sunmaktadır (Bowen, 2009, ss. 403-404). Bu kapsamda halkla ilişkilerin filmlerde ve gazete haberlerinde nasıl sunulduğu çeşitli araştırmalara konu olmuştur. 
Spicer (1993, ss. 53-57) yazılı basında halkla ilişkilere yönelik yedi tema olduğu sonucuna ulaşmıştır. Birincisi, bir gazeteciyi sorgulama açısından uzaklaştırmaya çalışan bir halkla ilișkiler uygulayıcısı gibi "dikkat dağıtıcı" olarak halkla ilișkiler; ikincisi "felaket" olarak halkla ilişkiler; üçüncüsü bir kereye mahsus felakete ya da dikkat dağıtmaya karşı "hakiki" bir halkla ilişkiler zorluğu; dördüncüsü "abartılı heyecan"; beşincisi "halkla ilişkiler tekniklerinin çoğunlukla gerçek yerine kullanıldığı halkla ilişkiler"; altıncısı "olumlu bir kamuoyu oluşturmak için devam eden bir mücadele olarak halkla ilişkiler"; yedincisi ise "düzgün konuşan, etkileyici ve içten bir uygulayıcıyı betimleyen halkla ilişkiler" olarak sıralanabilir. Bahsi geçen temalardan görüldüğü üzere halkla ilişkiler daha çok olumsuz bir içerik üzerinden sunulmaktadır.

Jo (2003, ss. 406-409) medyanın halkla ilişkiler terimini nasıl ele aldığını iki saygın gazeteden ve üç akşam haber yayınından hareketle toplam 303 içerik üzerinden incelemiştir. Araştırma sonuçları halkla ilişkilerin en fazla itibar yönetimi ve ikna ile ilişkili olduğunu, incelenen içeriklerin daha çok olumsuz bir şekilde sunulduğunu ortaya koymuştur.

Jo'nun araştırması (2003, s. 406) haberlerin, halkla ilişkiler terimini öncelikle imaj oluşturma, itibar yönetimi ve ikna etme çabalarına yönelik kullandığını göstermiştir. Bu kapsamda Jo, halkla ilişkiler terimlerinin kullanılmasının, bir kurumun ürünlerini veya hizmetlerini tanıtmak için tanıtım, imaj, ikna kampanyaları ve pazarlama çabalarına atıfta bulunduğunu; halkla ilişkilerin ilişki yönetimi olarak adlandırılan son zamanlardaki vurgusunun aksine halkla ilişkilerin normatif tanımı ile haberlerde kullanımı arasında bir tutarsızlık olduğunu dile getirmektedir.

Henderson (1998) 1995-1996 yılları arasında halkla ilişkiler teriminin popüler basında nasıl kullanıldığını değerlendirmek için toplam 100 yazıdan oluşan bir analiz gerçekleştirmiştir. Yazılarda kullanılan halkla ilişkiler teriminin anlamının, bu anlamın doğruluğunun ve terimi kullanan kişinin analiz edildiği çalışmada, terimin olumsuz bir çağrıșım oluşturacak şekilde kullanıldığı saptanmıştır.

Keenan (1996) 1980 ile 1995 yılları arasında üç büyük televizyon ağında, halkla ilişkiler anahtar kelimesini içeren bütün akşam haberlerini incelemiştir. Araştırma sonucunda basın ajansı / duyurum modelinin, halkla ilişkilerin nasıl çalıştığına ve mesleğin içeriğine ilişkin en fazla öne çıkan model olduğu; halkla ilişkiler ile ilgili haberlerin yarısından fazlasının nötr; çoğunluğunun ise olumsuz bir tonda olduğu ortaya çıkmıştır.

Freitag ve Stokes (2009, s. 105) halkla ilişkiler profesyonellerine ve onların faaliyetlerine yönelik göz kamaştırıcı ve gerçekçi olmayan medya tasvirinin mesleğin yönetim boyutunda yer alma çabalarını olumsuz etkilediğini ifade etmektedir. Parsons da (2016, s. 13) halkla ilişkilerin televizyonda ve diğer popüler kültür medyasında temsilinin, bu kavramı yalnızca çok sayıda kamunun zihninde pekiştirme görevi gördüğünü dile getirmektedir.

Moloney (2006) halkla ilişkilerin gelişmesine rağmen halkla ilişkilerin, halkla ilişsilerinin zayıf bir durumda olduğunu belirtmektedir. Fitch de (2015, s. 612) halkla ilişkiler faaliyetlerinin kurgusal temsilinin çok açık olmadığını, söz konusu temsilin anlatı ve genel bağlamından ayrı tutularak veya halkla ilişkiler endüstrisinin "gerçekliğinin" temsili olarak anlaşılamayacağını ifade etmektedir. 
Yapılan çalışmalardan hareketle medyada halkla ilişkilerin duyurum / basın ajansından biraz daha fazlası olduğu görülmektedir. Haber medyası, halkla ilişkilerin diğer işlevlerinden, özellikle de daha deneyimli uygulayıcıların sık sık uyguladığı yönetsel rollerden habersiz olma veya bu rolleri görmezden gelme eğilimindedir (Bowen, 2009, s. 403). Dolayısıyla halkla ilişkileri daha çok medyada ücretsiz bir şekilde yer almak şeklinde konumlandırmanın alanın gerektirdiği yönetimsel rolleri göz ardı edeceği çıkarımında bulunulabilir. Diğer yandan Plowman (2005, s. 131) halkla ilişkilerin paradokslarla dolu olduğunu, kuruma ve bu kuruma etki eden kamuya hizmet ettiğini, kamuyu ikna etmeye çalıştığını fakat alanın da ikna edilebildiğini, yüksek düzeyde bir etik anlayış içerebileceği gibi manipülatif de olabileceğini dile getirerek halkla ilişkilerin yaratıcı ve teknik rolde mükemmel bir şekilde işleyebileceğini ancak kurumlarda daha stratejik bir yönetim rolü üstlenmeye yönelik talebin de arttığını ifade etmektedir.

\section{Yöntem}

Halkla ilişkilerin gazetelerdeki sunumunu incelemeyi amaçlayan çalışmanın temel sorusu "gazetelerde halkla ilişkiler terimi nasıl sunulmaktadır?" şeklinde yapılandırılmıştır. Araştırma sorusunu yanıtlamak için medya tasviri araştırmalarında en fazla öne çıkan araştırma tekniklerinden biri olan içerik analizinden (Robinson, 2009, s. 501) yararlanılmıştır.

İçerik analizinde metin, anlamsal iletişimi oluşturan kelimeler, işaretler, imgeler ve filmler gibi ürünler olabilir (Hammond ve Wellington, 2013, s. 34). İçerik analizi, medya etkisine neden olduğu iddia edilen medya mesajlarının belirli niteliklerinin varlığını, yokluğunu veya miktarını incelemek amacıyla sıklıkla kullanılmaktadır (Bryant, Thompson ve Finklea, 2013, s. 17). Metinsel materyallerin sistematik olarak analiz edildiği ve bu materyallerden çıkarımlar yapıldığı içerik analizi (Cargan, 2007, s. 94), "örneklem seçimi”, "analiz kategorilerinin tanımlanması", "verileri inceleme ve kodlama”, "veri analizi" ve "bulgular temelinde sonucu düzenleme" olmak üzere beş aşamada yürütülmektedir (Bignell, 2004, s. 211).

Araştırma kapsamında 01.09.2019- 31.10.2019 tarihleri arasında yüksek tiraja sahip olan gazeteler arasında yer alan (alfabetik sıraya göre) Hürriyet, Posta, Sabah ve Sözcü Gazetelerinin web sitelerindeki arşiv sayılarında "halkla ilişkiler" terimini içeren toplam 73 haber analiz edilmiştir. Haber kavramı, köşe yazıları ve röportajları da içerecek şekilde kullanılmıştır. Söz konusu gazeteler ve tarih aralığı "amaçlı tesadüfi örneklem" seçimi tekniğinden hareketle seçilmiştir.

Miles ve Huberman (1994, s. 28) amaçlı örneklem potansiyelinin büyük olduğu durumlarda amaçlı tesadüfi örneklemin, örnekleme güvenirlik kattığını ifade etmektedir. Tesadüfi örnekleme, küçük bir örneklem grubundan oluşsa dahi sonuçların güvenirliğini artırmaktadır. Öte yandan, amaçlı tesadüfi örneklemde amaç, temsiliyetten ziyade güvenirlik olduğundan bu örnekleme tekniği istatistiksel genellemeler yapılmasına izin vermemektedir (Patton, 2002, ss. 240-241). Bu durum da çalışmanın temel sinırlılıklarından biridir. Dört gazete yüksek bir tiraja sahip olduğundan, Auriacombe'nin (2016, s. 9) içerik analizinde, örneklem seçiminin büyük ölçüde analiz birimine bağlı olduğu çıkarımından ve bu gazetelerin okunma oranlarının yüksek olduğu varsayımından hareketle analiz birimi açısından da yargısal örneklemin yapısına uygun olarak yoğun bir bilgi kaynağı sunacakları (Patton, 2002, ss. 240-241) varsayımından yola çıkılarak örneklem olarak seçilmiştir. 
Araştırmada tekrar eden haberler kapsam dışı bırakılmıştır. Diğer bir deyişle bir gazetede yer alan haber, başka bir gazetede benzer bir içerik ile yer almış ise söz konusu içerik tekrar içerik olarak kabul edilmiş ve örnekleme dahil edilmemiştir. Dolayısıyla çalışmanın analiz birimi, içeriğinde "halkla ilişkiler" teriminin geçtiği her bir haberdir.

Analiz kategorileri Hutton (1999), Park (2001), Jo (2003) ve Yoo ve Jo'nun (2014) çalışmalarından hareketle oluşturulmuştur. Bu kapsamda toplam dört kategori belirlenmiștir. Bahsi geçen kategorilere ve kategorilerin operasyonel tanımlarına Tablo 1 'de değinilmektedir.

Tablo 1: İçerik Analizi Kategorileri

\begin{tabular}{|c|c|}
\hline \multirow{3}{*}{$\begin{array}{l}\text { İçerik türü } \\
\text { Park (2001, s. 412) }\end{array}$} & Haber \\
\hline & Köşe yazısı \\
\hline & Röportaj \\
\hline \multirow{3}{*}{$\begin{array}{l}\text { Kurum / Kişi } \\
\text { Yoo ve Jo (2014, s. 504) }\end{array}$} & Kar amacı taşıyan \\
\hline & Kar amacı taşımayan \\
\hline & Kişi \\
\hline \multirow{6}{*}{$\begin{array}{l}\text { Terimin kullanım amacı } \\
\text { Jo (2003, s. 402) } \\
\text { Hutton (1999, ss. 205-208) }\end{array}$} & $\begin{array}{l}\text { İkna: Proaktif olup hedef kitleyi, kuruma / kişiye fayda } \\
\text { sağlayacak şekilde düşünmeye veya hareket etmeye } \\
\text { yönelik ikna edici halkla ilişkiler yaklaşımını içerir. }\end{array}$ \\
\hline & $\begin{array}{l}\text { Savunuculuk: İkna ile benzer olsa da kaynağını tartışmadan veya aktif } \\
\text { bir karşııktan aldığından iknadan farklıdır. Dolayısıyla, halkla ilişkiler } \\
\text { savunuculuğu çabaları bir kriz veya başka bir etken tarafından tetiklenir. }\end{array}$ \\
\hline & Kamuyu bilgilendirme: Halkla ilişkiler bir bilgi kaynağı işlevi görür. \\
\hline & $\begin{array}{l}\text { Sosyal amaca yönelik halkla ilişkiler: Reaktif olabileceği ve kamusal } \\
\text { bir olay tarafından başlatılacağı için savunuculuğa benzer. Bununla } \\
\text { birlikte, sosyal amaca yönelik halkla ilişkiler, herhangi bir özel ilgi grubu } \\
\text { veya bireyden ziyade daha geniş bir kamu faydasına yöneliktir. }\end{array}$ \\
\hline & İmaj-itibar: Kurumun / kişinin imajına ve itibarına odaklanılır. \\
\hline & $\begin{array}{l}\text { İlişki yönetimi: Bir kurum / kişi ile onun kamuları arasında karşılıklı faydaları } \\
\text { ve değerleri belirlemeye yönelik bir halkla ilişkiler uygulamasını ifade eder. }\end{array}$ \\
\hline \multirow{3}{*}{$\begin{array}{l}\text { Ton } \\
\text { Jo }(2003, \text { ss. 402-403) }\end{array}$} & $\begin{array}{l}\text { Olumlu: Halkla ilişkilerin olumlu rolünü, halkla ilişkilerin doğru anlamını ve } \\
\text { bir kuruma faydalı bir çıktı sunduğunu gösteren olumlu bir anlamdır. }\end{array}$ \\
\hline & $\begin{array}{l}\text { Olumsuz: İmaj çelişkisi ya da bir kurumun itibar yönetiminin } \\
\text { başarısızlığı gibi halkla ilişkilerin olumsuz bir şekilde sunulmasıdır. }\end{array}$ \\
\hline & $\begin{array}{l}\text { Nötr: Halkla ilişkiler stratejisi ve halkla ilişkiler kampanyası gibi genel } \\
\text { bir kullanımı içeren olumlu ya da olumsuz olmayan ifadelerdir. }\end{array}$ \\
\hline
\end{tabular}

İçerik analizi kategorileri dört temel kategoriden oluşmaktadır. İçerik türü, kurum ve ton kategorilerinin üç; halkla ilişkiler teriminin kullanım amacı kategorisinin ise altı alt kategorisi bulunmaktadır. Heath ve Coombs (2006, ss. 33-36) halkla ilişkilere gereksinim duyan kurumları "ticari kurumlar, kamu kurumları ve kar amacı taşımayan kurumlar" olmak üzere üçe ayırmaktadır. Bu çalışmada ticari kurumlar kar amacı taşıyan, kamu kurumları ise kar amacı taşımayan kurumlar kapsamında değerlendirilmiştir. Öte yandan Jo (2003) ve Hutton'ın (1999) kategorilerine "meslek olarak halkla ilişkiler" ve "eğitim alanı halkla ilişkiler" olmak üzere iki kategori daha eklenmiștir. Meslek olarak halkla ilişkiler ifadesi, halkla ilişkilerin mesleki boyutunu ön plana çıkaran içerikler için kullanılmış iken; eğitim alanı olarak halkla ilişkiler ifadesi ise halkla ilişkilerin bir eğitim alanı olma boyutunu vurgulayan içerikler için kullanılmıştır. 


\section{Bulgular}

Tablo 2, 3, 4 ve 5'te sırasıyla içerik türü, kurum / kişi, terimin kullanım amacı ve ton kategorilerine ilişkin frekans analizlerine; 6'da ise terimin kullanım amacı ile kurum arasındaki ilişkiye yönelik karşılaştırmalı analize değinilmektedir.

Tablo 2: İçerik Türü

\begin{tabular}{|l|c|c|}
\hline İçerik & Frekans & Yüzde \\
\hline Haber & 64 & 87,7 \\
\hline Köşe yazısı & 9 & 12,3 \\
\hline Röportaj & - & - \\
\hline Toplam & 73 & 100 \\
\hline
\end{tabular}

İncelenen içeriklerin \%87,7'sini haberler, \%12,3'ünü ise köșe yazıları oluşturmaktadır. Röportaj türünde ise halkla ilişkiler terimine rastlanmamıştır.

Tablo 3: Kurum / Kişi

\begin{tabular}{|l|c|c|}
\hline Kurum & Frekans & Yüzde \\
\hline Kar amacı taşımayan & 38 & 52,1 \\
\hline Kar amacı taşıyan & 12 & 16,4 \\
\hline Kişi & 23 & 31,5 \\
\hline Toplam & 73 & 100 \\
\hline
\end{tabular}

Halkla ilişkiler teriminin hangi tür kurumlar bağlamında kullanıldığına ilişkin bulgulara bakıldığında incelenen 73 içeriğin 38'inde terimin kar amacı taşımayan bir kurum, 12 'sinde ise kar amacı taşıyan bir kurum bağlamında kullanıldığı görülmektedir. Toplam 23 içerikte ise halkla ilişkiler terimi bir kişi bağlamında kullanılmıştır.

Tablo 4: Terimin Kullanım Amacl

\begin{tabular}{|l|c|c|}
\hline Amaç & Frekans & Yüzde \\
\hline Kamuyu bilgilendirme & 33 & 45,2 \\
\hline Meslek olarak halkla ilişkiler & 18 & 24,7 \\
\hline İmaj & 12 & 16,4 \\
\hline Eğitim alanı olarak halkla ilişkiler & 8 & 11 \\
\hline İkna & 1 & 1,4 \\
\hline Sosyal amaç & 1 & 1,4 \\
\hline Savunuculuk & - & - \\
\hline İlişki yönetimi & - & - \\
\hline Toplam & 73 & 100 \\
\hline
\end{tabular}

Tablo 4'te halkla ilişkiler teriminin incelenen gazete içeriklerinde kullanım amacına yönelik bulgular yer almaktadır. Tabloya göre en fazla öne çıkan amaç kamuyu bilgilendirme olup bu amacı sırası ile meslek olarak halkla ilişkiler, imaj, eğitim alanı olarak halkla ilişkiler, ikna ve sosyal amaca yönelik halkla ilişkiler amaçları izlemiştir. Savunuculuk ve ilişki yönetimi amaçlarına ise hiçbir haber içeriğinde rastlanmamıştır. Kamuyu bilgilendirme amacının öne çıkması, kamulara doğru bilginin yayılması gerekliliğini vurgulayan "kamuyu bilgilendirme" modelini (Heath ve Coombs, 2006, s. 474) çağrıştıracak şekilde halkla ilişkilerin daha çok bilgilendirme fonksiyonuna vurgu yapar niteliktedir. Meslek olarak halkla ilişkiler ise halkla ilişkilerin herhangi bir işlevini öne çıkarmadan terimin sadece mesleki bir anlamı ifade edecek şekilde kullanılmasını vurgulamaktadır. 
Halkla ilişkilerin imaj ve itibar yapılandırma sürecindeki işlevi düşünüldügünde imajın bütün amaçlar arasında üçüncü sırada yer alması somut bir görünüm kazanmaktadır. Eğitim alanı olarak halkla ilişkiler de meslek olarak halkla ilişkiler amacındaki gibi alanın eğitim boyutuna vurgu yapmaktadır. İkna amacı sadece bir haberde öne çıkmış olup söz konusu haberde bir halkla ilişkiler uygulama alanı olan lobicilik faaliyeti üzerinden yürütülen bir ikna pratiğine vurgu yapılmıştır. Lobiciliğin bir ikna aracı olması (Jackson, 2013, s. 121) incelenen içerik ile de somutlaşmaktadır.

İkna amacında olduğu gibi sosyal amaç da yalnızca bir haberde öne çıkarak halkla ilişkilerin bir diğer uygulama alanı olan sosyal sorumluluk faaliyeti üzerinden aktarılmıştır. Öte yandan, halkla ilişkilerin savunuculuk ve ilişki yönetimi amaçları ise hiçbir haber içeriğinde yer almamıştır. Kamunun faydasına hizmet etmeleri gereken halkla ilişkiler profesyonellerinin rollerinden biri de savunuculuk (Fitzpatrick ve Bronstein, 2006, s. ix) olup örneklem kapsamına dahil olan içeriklerde söz konusu amaca rastlanmamıştır. Ledinghman ve Bruning'in (2000, s. xiii) belirttiği gibi halkla ilişkilerin şekillenmesi ve işlevi konularında çeşitli bakış açılarından en ilgi çekici olanlarından biri de ilişki yönetimidir. Dolayısıyla halkla ilişkilerin ilgili kamularla ilişki kurması ve bu ilişkiyi yönetmesi gerektiği düşünüldüğünde ilişki amacına yönelik içeriğin yer almaması olumsuz bir durum olarak dikkat çekmektedir.

Tablo 5: Ton

\begin{tabular}{|l|c|c|}
\hline Ton & Frekans & Yüzde \\
\hline Nötr & 71 & 97,3 \\
\hline Olumlu & 2 & 2,7 \\
\hline Olumsuz & - & - \\
\hline Toplam & 73 & 100 \\
\hline
\end{tabular}

İncelenen içeriklerin 71'inde halkla ilişkiler nötr bir şekilde, 2'sinde ise olumlu bir şekilde kullanılmıştır. Halkla ilişkiler terimini olumsuz bir şekilde niteleyen bir içeriğe ise rastlanmamıștır. Terimin olumlu bağlamda kullanıldığı iki haberden ilkinin odağını bir halkla ilişkiler ajansının yürütmüş olduğu sosyal sorumluluk kampanyası ile "toplumla ilişkiler" kategorisinde almış olduğu ödül; ikincisinin ise kent imajının tanıtımında halkla ilişkilerin rolünü vurgulayan bir içerik oluşturmaktadır.

Konu ile ilgili Henderson (1998) ve Jo (2003) tarafından yapılan çalışmalarda halkla ilişkilerin daha çok olumsuz bir ton ile yansıtıldığı sonucuna ulaşılmış iken bu çalışmada olumsuz bir tona rastlanmamıştır. Halkla ilişkilere yönelik negatif bir içeriğin olmaması terimin halkla ilişkileri bağlamında olumlu bir durum olarak yorumlanabilir. Medya ilişkileri açısından da kavramın olumsuz bir söylem ile yansıtılmaması medyanın, halkla ilişkiler açısından hem "bilgi yayma" hem de kurumu ve kurumun etkinliklerini, ürünlerini "izleme aracı" olma (Johnston, 2007, s. 5) özelliği kapsamında önem taşımaktadır. Diğer yandan incelenen içeriklerin \%45,2'sinde halkla ilişkilerin kamuyu bilgilendirme amacı bağlamında kullanılması söz konusu bulgunun nedenlerinden biri olabilir. Öyle ki bilgilendirme amacında imaj, iknadan ve savunuculuktan farklı olarak halkla ilişkilerin bilgi aktarma işlevine odaklanıldığı; imaj, ikna ve savunuculuk amaçlarında ise kurumun daha fazla öne çıkarılarak çoğunlukla iknaya dönük bir iletişimsel içeriğe odaklanıldığı belirtilebilir. 
Tablo 6: Terimin Kullanım Amacı ile Kurum Arasındaki İlișki

\begin{tabular}{|c|c|c|c|c|}
\hline \multirow{2}{*}{ Amaç } & \multicolumn{3}{|c|}{ Kurum / Kişi } & \multirow{2}{*}{ Toplam } \\
\hline & Kar amacı taşıyan & Kar amacı taşımayan & Kişi & \\
\hline Bilgilendirme & $\begin{array}{c}7 \\
\% 21,2\end{array}$ & $\begin{array}{c}26 \\
\% 78,8\end{array}$ & - & $\begin{array}{c}33 \\
\% 100\end{array}$ \\
\hline $\begin{array}{l}\text { Meslek olarak } \\
\text { halkla ilişkiler }\end{array}$ & $\begin{array}{c}1 \\
\% 5,6\end{array}$ & $\begin{array}{c}3 \\
\% 16,7\end{array}$ & $\begin{array}{c}14 \\
\% 77,8\end{array}$ & $\begin{array}{c}18 \\
\% 100\end{array}$ \\
\hline İmaj & $\begin{array}{c}2 \\
\% 16,7\end{array}$ & $\begin{array}{c}8 \\
\% 66,7 \\
\end{array}$ & $\begin{array}{c}2 \\
\% 16,7\end{array}$ & $\begin{array}{c}12 \\
\% 100\end{array}$ \\
\hline $\begin{array}{l}\text { Eğitim alanı olarak } \\
\text { halkla ilişkiler }\end{array}$ & - & $\begin{array}{c}1 \\
\% 12,5 \\
\end{array}$ & $\begin{array}{c}7 \\
\% 87,5\end{array}$ & $\begin{array}{c}8 \\
\% 100 \\
\end{array}$ \\
\hline İkna & $\begin{array}{c}1 \\
\% 100\end{array}$ & - & - & $\begin{array}{c}1 \\
\% 100\end{array}$ \\
\hline Sosyal amaç & $\begin{array}{c}1 \\
\% 100\end{array}$ & - & - & $\begin{array}{c}1 \\
\% 100\end{array}$ \\
\hline Toplam & 12 & 38 & 23 & 73 \\
\hline
\end{tabular}

Tablo 6'da halkla ilişkiler teriminin kullanım amacı ile kurum arasındaki ilişkiye yönelik bulgulara değinilmektedir. Bilgilendirme amacı taşıyan içeriklerin \%78,8'i kar amacı taşımayan kurumlara yönelik iken, \%21,2'si ise kar amacı taşıyan kurumlara yöneliktir. Meslek olarak halkla ilişkiler amacında \%77,8 ile kişilerin belirgin olduğu görülmektedir. $\mathrm{Bu}$ kapsamda halkla ilişkiler müdürü, basın ve halkla ilişkiler müşaviri, halkla ilişkiler daire başkanı, halkla ilişkiler uzmanı şeklinde mesleki unvanların içeriklerde yer aldığı görülmüştür.

İmaj amaçlı içeriklerin \%66,7'sinin kar amacı taşımayan kurumlara yönelik olduğu tespit edilmiştir. Eğitim alanı olarak halkla ilişkiler amacında \%87,5 ile kişilerin belirgin olduğu saptanmıștır. İncelenen gazete içeriklerinde ikna amacının ve sosyal amaca yönelik halkla ilişkilerin ise kar amacı taşıyan kurumlar kapsamında kullanıldığı sonucuna ulaşılmıştır. Halkla ilişkiler teriminin kullanım amacı ile kurum arasında anlamlı bir ilişkinin olduğu tespit edilmiştir $\left(X^{2}=56,423 ; p=, 000<0,05\right)$. Diğer bir anlatımla halkla ilişkiler teriminin kullanım amacı kurum / kişi açısından anlamlı bir farklılık göstermektedir.

\section{Sonuç}

Çeşitli araştırma ve uzmanlık alanlarının medyada nasıl temsil edildiği ve sunulduğu okuyucuların / izleyici ve dinleyicilerin söz konusu araştırma ve uzmanlık alanlarına yönelik algılarını etkilemeye yönelik bir potansiyel taşımaktadır. Medyanın çeşitli içerikleri ve kavramları belirli şekillerde çerçeveleyip sunması bu içerikleri ve kavramları medya bağlamında incelemeyi mümkün kılmaktadır. Hem bir araștırma hem de bir uzmanlık alanı olarak halkla ilişkilerin de medyada nasıl temsil edildiği çeşitli araştırmalara konu olmuştur. $\mathrm{Bu}$ araştırmalar film içeriklerinden, gazete içeriklerine kadar birtakım medya temel alınarak yürütülmüștür (Henderson, 1998; Keenan, 1996; Jo, 2003; Hutton ve Mak, 2014). Bahsi geçen araştırmaların ortak sonucunun halkla ilişkilerin çoğunlukla medyada olumsuz bir şekilde sunulduğudur.

Halkla ilişkilerin, halkla ilişkilerinin medya aracılığıyla nasıl sunulduğuna odaklanan bu araștırmada dört gazete üzerinden "halkla ilişkiler" terimini içeren toplam 73 haber içerik türü, kurum / kişi, terimin kullanım amacı ve ton kategorileri açısından analiz edilmiştir. İncelenen haberlerde halkla ilişkilerin en fazla kar amacı taşımayan kurumlara yönelik fonksiyonu öne çıkmıştır. Halkla ilişkilerin sadece kar amacı taşıyan kurumlara yönelik bir iletişim fonksiyonu olmadığı, kar amacı taşımayan kurumların da ilgili kamulara yönelik bilgilendirme, ilişki ve iletişim inşası gibi amaçlara yöneldikleri belirlenmiştir. 
Dolayısıyla halkla ilişkiler teriminde geçen ilişki kelimesinin içeriğine uygun olarak kar amacı taşımayan kurumlar için de halkla ilişkilerin önemli bir yönetim fonksiyonu olduğu söylenebilir. Neal da (2001, s. ix) medyanın, kar amacı taşımayan bir kurumun halkla ilişkiler temsilcisine karşı, ücretsiz bir duyurum elde etmeye çalışanlar olarak gördükleri kar amacı taşıyan bir kurumun halkla ilişkiler temsilcisine kıyasla daha duyarlı olduğunu dile getirmektedir.

Kurumlar kadar kişilere yönelik halkla ilişkiler içerikleri de çalışmada öne çıkmıştır. Kurumlar yerine kişilerin merkezde olduğu kişisel halkla ilişkiler uygulamalarında (Nessman, 2004, s. 24) kişilerin tıpkı kurumlar gibi planlanmış iletişim uygulamaları ile imaj ve itibar yapılandırma süreçlerine yönelmeleri gerektiği söylenebilir. Öte yandan çalışma bağlamında, kişilere yönelik halkla ilişkiler içeriklerinin daha çok mesleki bir alana ya da eğitim alanına referans gösterir bir şekilde yer aldığı saptanmıştır.

Halkla ilişkiler teriminin kullanım amacı; "kamuyu bilgilendirme, meslek olarak halkla ilişkiler, imaj, eğitim alanı olarak halkla ilişkiler, ikna, sosyal amaç, savunuculuk ve ilişki yönetimi" olmak üzere yedi alt kategoriden hareketle incelenmiştir. Bu doğrultuda en fazla öne çıkan amacın kamuyu bilgilendirme amacı olduğu görülmüştür. Bilgilendirme, halkla ilişkiler uygulayıcılarının temel rollerinden biridir. Halkla ilişkilerin doğru ve güvenilir bilgileri kamuya aktarması şeklinde yorumlanabilecek olan kamuyu bilgilendirme modeli de terimin bilgilendirme fonksiyonunu vurgulamaktadır. Diğer taraftan halkla ilişkileri sadece bilgilendirme fonksiyonu üzerinden konumlandırmak alanın stratejik boyutunu ikinci planda bırakmaktadır. Cutlip, Center ve Broom'un (2006) belirttiği gibi halkla ilişkiler stratejisi bir kurumun amaçlarına ve hedeflerine ulaşmak için yapabileceği eylemlerle ilgilidir. Halkla ilişkilerin bir yönetim fonksiyonu olması ilişki ve iletişim inşasındaki stratejik rolünü somutlaştırmaktadır.

Bilgilendirme halkla ilişkilerin rollerinden biri olsa da bilgilendirme șeklindeki teknik bir rolün halkla ilişkilerin temel amacı olmadığını da belirtmek gerekmektedir. Bu kapsamda Austin ve Pinkleton (2015, ss. 4-9) uygulayıcıların, sorunlara ve zorluklara taktiksel olarak değil stratejik olarak cevap verdiklerinde uzun süren sorunları çözmelerine veya önlenmelerine ve kilit paydaşların beklentilerine karşılıklı olarak faydalı bir şekilde yaklaşmalarına yardımcı olma ihtimallerinin çok daha yükseleceğini ve halkla ilişkilerde taktiksel yaklaşımdan, stratejik yönetimsel yaklaşıma geçişin araştırma/ planlama tekniklerini kullanım yeteneklerini gerektirdiğini ifade etmektedir. Dolayısıyla halkla ilişkilerin stratejik boyutunun genel olarak gazete içeriklerine yansımadığı çıkarımında bulunulabilir.

Meslek olarak halkla ilişkiler amacı, alanın belirli bir uzmanlık gerektiren yapısına vurgu yapmaktadır. İncelenen içeriklerde halkla ilişkileri mesleki bir bağlamda konumlandıran içerikler de yoğun bir şekilde yer almıştır. İmaj kavramı ise muhtemelen halkla ilişkilerin en fazla ilişkili olduğu kavramlardan biridir. Kamuların zihninde kurumun / kişinin yeri olarak tanımlanabilecek ya da Podnar'ın (2015, s. 141) deyimiyle "kurumun zihinsel kavrayıșı" olan imajı oluşturmada ve var olan imajı güçlendirmede halkla ilişkiler faaliyetleri rol oynamaktadır. İmaj ile ilişkili olan itibar yönetimi kavramı da bir halkla ilişkiler uygulama alanı olma özelliği taşımaktadır. İncelenen içeriklerin sekizinde ise halkla ilişkiler terimi bir eğitim alanı olarak sunulmuştur. Halkla ilişkiler eğitiminin daha çok habere konu olan kişi / kişiler üzerinden sunulduğu sonucuna ulaşılmıştır. 
İkna ve sosyal amaç ise sadece birer içerikte öne çıkmıştır. Algıyı, duyguyu, bilişi etkilemek ve/veya davranışı şekillendirmek, değiştirmek ve güçlendirmek için iletişimin kullanımı olarak tanımlanan ikna, özellikle kurum dışı paydaşlar açısından birçok halkla ilişkiler faaliyetinde önemli bir rol oynamaktadır (Pfau ve Wan, 2006, s. 89). Halkla ilişkilerin ikna edici bir iletişim pratiği olarak ilgili kamuların tutumlarını değiștirme ya da pekiștirme rolü olduğunu dile getirmek gerekmektedir. İkna amacı, incelenen haberlerde çok fazla öne çıkmamıştır.

Kurumsal sosyal sorumluluk şeklinde nitelendirilebilecek sosyal amaca yönelik halkla ilişkiler de terimin olumlu bir bağlamda sunulduğu haber içeriklerinden biridir. Halkla ilişkilerin özellikle kurumsal fayda yanı sıra toplumsal fayda oluşturma boyutunu vurgulaması bakımından sosyal amaç içeriklerde çok görünür olmasa da kurumların sosyal sorumluluk anlayışı ile hareket etmeleri gerekliliğini somutlaştırması bakımından önem taşımaktadır. Savunuculuk ve ilişki yönetimi amaçlarına ise hiçbir içerikte rastlanmamıştır. Yukarıda dile getirildiği gibi halkla ilişkilerin temel amaçlarından biri olan ilişki geliştirmenin incelenen içeriklerde yer almaması terimin gazetelerdeki sunumu açısından olumsuz bir durumdur.

Çalışmada son olarak üzerinde durulan kategori ise halkla ilişkiler teriminin nasıl bir ton ile sunulduğudur. Konu ile ilgili daha önce yapılan araştırmalarda halkla ilişkilerin medyada daha çok olumsuz bir ton ile sunulduğu belirlense de bu çalışmada daha çok nötr bir şekilde sunulduğu belirlenmiştir. Özellikle terimin, kamuyu bilgilendirme amacının öne çıkması nötr bir şekilde sunulmasının olası nedenlerinden birini oluşturabilir. Bilgilendirme daha çok objektif bilgilerin aktarımı yaklaşımına dayandığından bilgilendirme pratiğini niteleyen nötr yaklaşımın, halkla ilişsiler teriminin de nötr bir şekilde sunulması ile ilişkili olduğu söylenebilir. Halkla ilişkiler teriminin haber içeriklerine olumsuz bir şekilde yansıtılmaması terimin medyadaki sunumu açısından olumlu bir durum olarak değerlendirilebilir.

\section{Kaynakça}

Auriacombe, C. J. (2016). Towards the construction of unobtrusive research techniques: Critical considerations when conducting a literature analysis. African Journal of Public Affairs. 9(4), 1-19.

Austin, E. W., \& Pinkleton, B. E. (2015). Strategic public relations management: Planning and managing effective communication campaigns. Abingdon, Oxon: Routledge.

Bentele, G., \& Wehmeier, S. (2003). From literary bureaus to a modern profession: The development and current structure of public relations in Germany. In K. Sriramesh and D. Vercic (Eds.), The global public relations handbook: Theory, research, and practice (pp. 199-221). Mahway, New Jersey: Lawrence Erlbaum.

Bentele, G., \& Junghänel, I. (2004). Germany. In B. Van Ruler and D. Vercic, D. (Eds.), Public relations and communication management in Europe: Anation-by-nation introduction to public relations theory and practice (pp. 153-168). Berlin: De Gruyter.

Bignell, J. (2004). An introduction to television studies. London: Routledge.

Bowen, S. A. (2009). All glamour, no substance? How public relations majors and potential majors in an exemplar program view the industry and function. Public Relations Review, 35(4), 402-410. 
Bryant, J., Thompson, S., \& Finklea, B. W. (2013). Fundamentals of media effects. Long Grove, IL: Waveland Press.

Callison, C. (2001). Do PR practitioners have a PR problem?: The effect of associating a source with public relations and client-negative news on audience perception of credibility. Journal of Public Relations Research, 13(3), 219-234.

Cargan, L. (2007). Doing social research. Lanham, Maryland: Rowman \& Littlefield.

Chorazy, E., \& Harrington, S. (2017). Fluff, frivolity, and the fabulous Samantha Jones: Representations of public relations in entertainment. In S. Harrington (Ed.), Entertainment values (pp. 229-249). London: Palgrave Macmillan.

Croteau, D., \& Hoynes, W. (2003). Media/society: Industries, images, and audiences. Thousand Oaks, CA: Sage.

Cutlip, S. M., Center, A. H., \& Broom G. M. (2006). Effective public relations (9th ed.). Englewood Cliffs, NJ: Prentice Hall.

Fitch, K. (2015). Promoting the vampire rights amendment: public relations, postfeminism and True Blood. Public Relations Review, 41(5), 607-614.

Fitzpatrick, K., \& Bronstein, C. (2006). Introduction: Toward a definitional framework for responsible advocacy. In K. Fitzpatrick, K. and C. Bronstein (Eds.), Ethics in public relations: Responsible advocacy (pp. ix-xiv). Thousand Oaks, CA: Sage.

Freitag, A. R., \& Stokes, A. Q. (2009). Global public relations: Spanning borders, spanning cultures. Abingdon, Oxon: Routledge.

Hall, S. (1997). Representation: Cultural representations and signifying practices. London: Sage.

Hammond, M., \& Wellington, J. (2013). Research methods: The key concepts. Abingdon, Oxon: Routledge.

Heath, R. L., \& Coombs, W. T. (2006). Today's public relations: An introduction. Thousand Oaks, CA: Sage.

Henderson, J. K. (1998). Negative connotations in the use of the term "public relations" in the print media. Public Relations Review, 24(1), 45-54.

Hon, L. C., \& Grunig J. E. (1999). Guidelines for measuring relationships in public relations. Gainesville, FL: The Institute For Public Relations, University of Florida, Gainesville

Hutton, J. G. (1999). The definition, dimensions, and domain of public relations. Public Relations Review, 25(2), 199-214.

Hutton, J. G., \& Mak, A. K. Y. (2014). Is a picture worth a thousand words? Using films and television shows to teach public relations. Public Relations Review, 40(3), 585-594.

Jackson, N. (2013). Promoting and marketing events: Theory and practice. Abingdon, Oxon: Routledge.

Jo, S. (2003). The portrayal of public relations in the news media. Mass Communication and Society, 6(4), 397-411.

Johnston, J. (2007). Media relations: Issues and strategies. Crows Nest, Australia: Allen \& Unwin. 
Keenan, K. L. (1996). Network television news coverage of public relations: An exploratory census of content. Public Relations Review, 22, 215-231.

King, D. L. (2000). Using videos to teach mass media and society from a critical perspective. Teaching Sociology, 28, 232-240.

Lambert, C. A. (2017). Post-racial public relations on primetime television: How Scandal represents Olivia Pope. Public Relations Review, 43(4), 750-754.

Lambert, C. A., Strauss, J., \& Tindall, N. T. J. (2016). Public relations representation in popula culture: A Scandal on primetime television. In A. F. Herrmann and A. Herbig (Eds.), Communication perspectives on popular culture (pp. 89-99). Lanham, Maryland: Lexington Books.

Ledingham, J. A., \& Bruning, S. D. (2000). Introduction: Background and Current Trends in the Study of Relationship Management. In J. A. Ledingham and S. D. Bruning (Eds.), Public relations as relationship management: A relational approach to the study and practice of public relations (pp. xi-xvii). Mahway, New Jersey: Lawrence Erlbaum.

Lee, M. (2004). What does Hollywood think nonprofit CEOs do all day? Screen depictions of NGO management. Public Organization Review, 4(2), 157-176.

Mac, S., \& Blum, D. (2013). Uncovering images of teaching: Towards a teacher - activist ideal. In E. A. Janak and D. F. Blum (Eds.), The pedagogy of pop: theoretical and practical strategies for success (pp. 45-60). Lanham, Maryland: Lexington Books.

Miles, M. B., \& Huberman, A. M. (1994). Qualitative data analysis. Thousand Oaks, CA: Sage.

Miller, K. S. (1999). Public relations in film and fiction: 1930 to 1995. Journal of Public Relations Research, 11(1), 3-28.

Moloney, K. (2006). Rethinking public relations: PR propaganda and democracy. Abingdon, Oxon: Routledge.

Neal, K. A. (2001). A primer on non-profit PR: If charity begins at home... Sarasota, Florida: Pineapple Press.

Nessman, K. (2004). Austria. In B. Van Ruler and D. Vercic, D. (Eds.), Public relations and communication management in Europe: A nation-by-nation introduction to public relations theory and practice (pp. 13-28). Berlin: De Gruyter.

Park, J. (2001). Images of "Hong Bo (public relations)" and PR in Korean newspapers. Public Relations Review, 27(4), 403-420.

Parsons, P. J. (2016). Ethics in public relations: A guide to best practice. London: Kogan Page Publishers.

Patton, M. Q. (2002). Qualitative evaluation methods. Thousand Oaks, CA: Sage.

Penning, T. (2008). First impressions: US media portrayals of public relations in the 1920s. Journal of Communication Management, 12(4), 344-358.

Perse, E. M., \& Lambe, J. (2017). Media effects and society. Abingdon, Oxon: Routledge.

Pfau, M., \&Wan, H. H. (2006). Persuasion: An intrinsic function of public relations. In C. Botan and V. Hazleton, V. (Eds.), Public relations theory II (pp. 88-119). Mahwah, NJ: Lawrence Erlbaum. 
Plowman, K. D. (2005). Conflict, strategic management, and public relations. Public Relations Review, 31(1), 131-138.

Podnar, K. (2015). Corporate communication: A marketing viewpoint. Abingdon, Oxon: Routledge.

Robinson, J. D. (2009). Media portrayals and representations. In W. F. Eadie Ed.), 21st century communication: A reference handbook (pp. 497-505). Thousand Oaks, CA: Sage.

Saltzman, J. (2011). The image of the public relations practitioner in movies and television, 1901-2011. The IJPC Journal, 3, 1-50.

Spicer, C. (1993). Images of public relations in the print media. Journal of Public Relations Research, 5(1), 47-61.

Thurlow, A., \& Yue, A. R. (2015). A brief history of public relations in Canada. In W. W. Carney and L. A. Lymer (Eds.), Fundamentals of public relations and marketing communications in Canada (pp. 21-38). Alberta: The University of Alberta Press.

Trbic, B. (2007). This is not a pipe: An introduction to representation. Screen Education, 47, 86-91.

Yoo, J. W., \& Jo, S. (2014). A comparative analysis of the perception of public relations in Chinese and South Korean newspapers. Public Relations Review, 40(3), 503-505.

Zoch, L. M., Supa, D. W., \& VanTuyll, D. R. (2014). The portrayal of public relations in the era of Ivy Lee through the lens of the New York Times. Public Relations Review, 40(4), 723-732. 


\title{
An Analysis of Presentation of Public Relations in Newspapers
}

\author{
Özgür Kılınç (Asst. Prof. Dr.)
}

\section{Extended Abstract \\ Introduction}

Public relations is a management function for communication and relationship building. It can be said that the historical process of public relations is structured on persuasion, communication and relationship. On the other hand, although this communicative practice is basically defined as a management function, the way public relations are featured in the media, in other words, public relations of public relation is presented through a negative discourse in general. Although the field defines itself through the concepts of persuasion, communication and relationship or "initiative, interest and image" in Hutton's terms (1999, p. 205), there is a contradiction between the way the public relations field defines itself and the perception of the field.

The disconnect between how the public relations field defines itself and how the public understands this field can be explained by how public relations is portrayed in the media (Penning, 2008, p. 345). The objective of the study is to analyse the presentation of the concept of public relations in newspapers, based on the view that the way public relations is presented in the media can provide a better understanding of how the term and therefore the practice are perceived (Jo, 2003, p. 398). In line with this objective, 73 news stories containing the concept of public relations were analysed in four newspapers.

\section{Presentation of Public Relations in Media}

As a leading component of popular culture, films have the power to describe and influence the image of a particular subject, organisations or profession (Lee, 2004, p. 157). First of all, public relations, which work to manage information, image and stakeholder relations, play an important role in the modern media environment with its size and impact (Chorazy and Harrington, 2017, p. 229). Interest in the representation of public relations practitioners in films and television has become more widespread since the 1970s (Saltzman, 2011).

Jo (2003, pp. 406-409) analysed how the media handles the term public relations over a total of 303 content, based on two reputable newspapers and three evening news publications. The results of the research revealed that public relations was mostly associated with reputation management and persuasion, and the examined content was more negative than positive.

Henderson (1998) conducted an analysis of 100 articles between 1995 and 1996 to evaluate how the term public relations is used in the popular press. In the study, it was found that the term was used to create a negative connotation. Between 1980 and 1995, Keenan (1996) examined all the evening news on the three major television networks, including the keyword public relations. As a result of the research, the press agency / publicity model is the most prominent model regarding how public relations works and the content of the profession; more than half of the news on public relations are neutral; and the majority of them were in a negative tone. 
News media tend to be unaware of other functions of public relations, especially the managerial roles frequently used by more experienced practitioners (Bowen, 2009, p. 403). Therefore, it can be inferred that positioning public relations more as an unpaid media coverage will ignore the managerial roles required by the field.

\section{Method}

The main question of the study, which aims to examine the presentation of public relations in newspapers, is "how is the term public relations presented in newspapers?" Content analysis, one of the most prominent research techniques in media portrayal research (Robinson, 2009, p. 501), was used to answer the research question.

A total of 73 news stories containing the term "public relations" were analysed in Hürriyet, Posta, Sabah and Sözcü (in alphabetical order) newspapers between 01.09.2019 and 31.10.2019. The concept of news has also been used to include column articles and interview. The newspapers and the date range were selected by purposive random sampling and the recurring news coverage was excluded. In other words, if a news story in a newspaper was included with similar content in another newspaper, the content was considered as repetitive content and not included in the sampling. Therefore, the analysis unit of the study is each news article that contains the term "public relations."

The analysis categories are based on the studies of Hutton (1999), Park (2001), Jo (2003) and Yoo and Jo (2014). In this context, a total of four categories are defined: Content type, organisation / person, purpose of use of the term and tone. In this study, commercial organisations are evaluated within the scope of profit-making organisations and public organisations are evaluated within the scope of non-profit organisations. On the other hand, two other categories, "public relations as a profession" and "public relations as a field of education" were added to Jo (2003) and Hutton's (1999) categories. While the term public relations as a profession is used for the content that emphasize the professional dimension of public relations; the term public relations as a field of education is used for the content emphasizing the dimension of public relations as a field of education.

\section{Findings}

$87.7 \%$ of the content examined are news articles and $12.3 \%$ are column articles. The term public relations is not found in the interview genre. When we look the findings of which types of organisations the term public relations is used, it is observed that 38 of the 73 content examined use the term in the context of a non-profit organisations and 12 in the context of a profit-making organisations. In a total of 23 content, the term public relations was used in the context of a person.

The most prominent objective is public information and this objective was followed by public relations as a profession, image, public relations as an educational field, persuasion and cause-related. The purposes of advocacy and relationship management have not been found in any news content. The prominence of the purpose of public information emphasizes the more information function of public relations by evoking the "public information" model which emphasizes the necessity of disseminating accurate information to the public (Heath and Coombs, 2006, p. 474).

In 73 of the examined content, public relations was used in a neutral way and in two of them the content was used in a positive way. There was no content that negatively describes the term of public relations. The focus of the first two news articles in which 
the term is used in a positive context is the social responsibility campaign carried out by a public relations agency and the award it received in the "community relations" category; the second is a content highlighting the role of public relations in promoting the image of the city.

\section{Conclusion}

In the news examined, the function of public relations towards non-profit organisations has become prominent. The content of public relations aimed at individuals as well as organisations was prominent in the study. In personal public relations practices where people are at the centre instead of organisations (Nessman, 2004, p. 24), it can be said that people should focus on image and reputation structuring processes with planned communication practices such as organisations.

The most prominent purpose was public information. Information is one of the main roles of public relations practitioners. The public information model, which can be interpreted as public relations passing accurate and reliable information to the public, also emphasizes the information function of the term. On the other hand, positioning the public relations only through the information function leaves the strategic dimension of the field in second priority.

Previous research on the subject revealed that public relations was presented with a more negative tone in the media, but in this study it was determined that it was presented in a more neutral tone. In particular, the prominence of the term for information purposes may be one of the possible reasons for its presentation in a neutral tone. Since information is based more on the objective information transfer approach, it can be said that the neutral approach that describes the information practice is related to the neutral presentation of the term public relations. The fact that the term public relations is not reflected negatively in news content can be considered as a positive point in terms of the presentation of the term in the media.

Keywords: Public Relations, Public Relations in Media, Presentation of Public Relations. 